\title{
Species Distribution and Antifungal Susceptibility Profile of Candida spp. Bloodstream Isolates from Latin American Hospitals
}

\author{
Patrício Godoy, Iris Nora Tiraboschi*, Luiz Carlos Severo**, Beatriz Bustamante***, \\ Belinda Calvo****, Leila Paula de Almeida, Daniel Archimedes da Matta, \\ Arnaldo Lopes Colombo/ ${ }^{+}$
}

\begin{abstract}
Hospital São Paulo, Escola Paulista de Medicina, Universidade Federal de São Paulo, Rua Napoleão de Barros 740 - $7^{\circ}$ andar, 04023-062 São Paulo, SP, Brasil *Hospital de Clínicas “José de San Martín”, Universidad de Buenos Aires, Buenos Aires,

Argentina ** Instituto Especializado em Pesquisa e Diagnóstico, Santa Casa de Porto Alegre, Porto Alegre, RS, Brasil

***Hospital "Cayetano Heredia", Lima, Perú ****Hospital Universitário de Maracaibo, Universidad del Zulia (Luz), Maracaibo, Venezuela
\end{abstract}

From March 1999 to March 2000, we conducted a prospective multicenter study of candidemia involving five tertiary care hospitals from four countries in Latin America. Yeast isolates were identified by classical methods and the antifungal susceptibility profile was determined according to the National Committee for Clinical Laboratory Standards microbroth assay method.

During a 12 month-period we were able to collect a total of 103 bloodstream isolates of Candida spp. C. albicans was the most frequently isolated species accounting for $42 \%$ of all isolates. Non-albicans Candida species strains accounted for $58 \%$ of all episodes of candidemia and were mostly represented by $\mathrm{C}$. tropicalis $(24.2 \%)$ and $\mathrm{C}$. parapsilosis $(21.3 \%)$. It is noteworthy that we were able to identify two cases of C. lusitaniae from different institutions. In our casuistic, non-albicans Candida species isolates related to candidemic episodes were susceptible to fluconazole. Continuously surveillance programs are needed in order to identify possible changes in the species distribution and antifungal susceptibility patterns of yeasts that may occurs after increasing the use of azoles in Latin American hospitals.

Key words: candidemia - antifungal susceptibility - Candida spp.

A progressive increase in the frequency of candidemia has been observed, particularly among patients receiving antibiotics, immunosuppressive therapy, or parenteral nutrition, as well as among patients exposed to invasive medical procedures such as intravascular catheter, hemodialysis, and abdominal surgery (Lunel et al. 1999).

Despite Candida albicans is still considered the most frequently isolated species of candidemic patients, the emergence of non-albicans Candida species is clearly a concern. The resistance of non-C. albicans isolates to currently available antifungal drugs represents a major challenge for future empirical therapeutic and prophylactic strategies (Krcmery \& Barnes 2002).

Due to the lack of information related to the epidemiology of candidemia existing in our region, we conducted a multicenter study to evaluate the species distribution and antifungal susceptibility patterns of Candida spp. bloodstream isolates in Latin American hospitals.

\section{PATIENTS AND METHODS}

Data collection and clinical specimens - From March 1999 to March 2000, we conducted a prospective multicenter study of candidemia involving five tertiary

${ }^{+}$Corresponding author. Fax: +55-11-5549.6585. E-mail: lemidipa@vento.com.br

Received 5 July 2002

Accepted 23 January 2003 care hospitals from four countries in Latin America: Hospital Universitário de Maracaibo, Universidad del Zulia (Luz), Maracaibo, Venezuela, Hospital "Cayetano Heredia”, Lima, Peru, Hospital de Clínicas "José de San Martín”, Universidad de Buenos Aires, Argentina, Instituto Especializado em Pesquisa e Diagnóstico, Santa Casa de Porto Alegre, Brazil and Hospital São Paulo, Escola Paulista de Medicina, Universidade Federal de São Paulo, Brazil.

The centers were requested to send the isolated strains to the reference laboratory (Laboratório Especial de Micologia, Division of Infectious Diseases, Unifesp, São Paulo, Brazil) for further identification and antifungal susceptibility testing. In order to be included in this study the patient must have had at least one blood culture positive for Candida spp., drawn from a peripheral vein, and clinical evidence of sepsis.

Yeast identification procedures - The purity and viability of yeast original cultures were checked by plating yeast colonies on CHROMagar Candida (CHROMagar Microbiology Paris, France). C. albicans isolates were identified if they exhibited green colonies on CHROMagar Candida and produced chlamydoconidia on corn mealTween 80 agar. Non-albicans Candida species isolates were identified on the basis of their micromorphology on corn meal-Tween 80 agar and biochemical tests evaluated by using the commercial system ID 32C, bioMérieux Marcy l'Etoile, France (Warren \& Hazen 1995, Baumgartner et al. 1996).

In vitro susceptibility testing - Antifungal susceptibility tests were performed by using the broth microdilution assay according to the methodology recommended by 
the National Committee for Clinical Laboratory Standards (NCCLS), document M-27 A2. The following antifungal drugs, supplied by the manufacturers as pure standard compounds, were tested: amphotericin B, fluconazole, itraconazole and 5-flucytosine. Briefly, the medium used was RPMI-1640, with L-glutamine, without bicarbonate, and buffered at $\mathrm{pH} 7.0$ with $0.165 \mathrm{M}$ MOPS. The yeast inoculum suspension was prepared by using a spectrophotometer to obtain a final yeast concentration containing $0.5-2.5 \times 10^{3}$ cells $/ \mathrm{ml}$. The assays were incubated at $35^{\circ} \mathrm{C}$ for $48 \mathrm{~h}$. The minimal inhibitory concentration (MIC) for amphotericin B was considered the lowest tested concentration able to prevent visible growth. MIC for azoles was considered as the lowest tested concentration with a significant reduction (approximately $50 \%$ ) in growth compared to growth of a positive control (NCCLS 2002).

The breakpoints for azoles and 5-flucytosine MICs were those suggested by the NCCLS M27-A2. Due to a lack of consensus about the definition of MIC breakpoint for amphotericin B, arbitrary values were established according to values suggested by a previous study (Nguyen et al. 1998). Isolates with MICs $\leq 8 \mu \mathrm{g} / \mathrm{ml}$ for fluconazole, $\leq 4 \mu \mathrm{g} / \mathrm{ml}$ for 5 -flucytosine, $\leq 0.125 \mu \mathrm{g} / \mathrm{ml}$ for itraconazole, and $\leq 1 \mu \mathrm{g} / \mathrm{ml}$ for amphotericin B were considered susceptible. Isolates with MICs between 16 and $32 \mu \mathrm{g} / \mathrm{ml}$ for fluconazole, and 0.25 to $0.5 \mu \mathrm{g} / \mathrm{ml}$ for itraconazole, were considered to have reduced (dose-dependent) susceptibility (DDS). MICs $\geq 64 \mu \mathrm{g} / \mathrm{ml}$ for fluconazole, $\geq 32 \mu \mathrm{g} / \mathrm{ml}$ for 5-flucytosine, $\geq 1 \mu \mathrm{g} / \mathrm{ml}$ for itraconazole, and $\geq 2 \mu \mathrm{g} / \mathrm{ml}$ for amphotericin $\mathrm{B}$, were considered resistant (NCCLS M27-A2).

\section{RESULTS}

During a 12 month-period we were able to collect a total of 103 bloodstream isolates of Candida spp. $C$. albicans was the most frequently isolated species accounting for $42 \%$ of all isolates. As show in Table I, nonalbicans Candida species strains accounted for $58 \%$ of
TABLE I

Etiologic agents of 103 candidemic episodes

\begin{tabular}{lcc}
\hline Etiologic agent & $\mathrm{N}$ & $\%$ \\
\hline Candida albicans & 43 & 42 \\
Candida tropicalis & 25 & 24.2 \\
Candida parapsilosis & 22 & 21.3 \\
Candida glabrata & 8 & 7.7 \\
Candida guilliermondii & 3 & 2.9 \\
Candida lusitaniae & 2 & 1.9 \\
\hline
\end{tabular}

all episodes of candidemia and were mostly represented by C. tropicalis $(24.2 \%)$ and C. parapsilosis $(21.3 \%)$.

Table II shows $\mathrm{MIC}_{50}$ and $\mathrm{MIC}_{90}$ values exhibited by the four antifungal drugs tested against the most frequently isolated Candida spp. strains. C. albicans, $C$. tropicalis and $C$. parapsilosis isolates were all susceptible to fluconazole and amphotericin B.

Only one C. albicans isolate was resistant to 5flucytosine. Non-albicans Candida species isolates had higher azoles MIC values than $C$. albicans isolates but remained sensitive to low drug concentrations of amphotericin B. C. glabrata isolates had fluconazole $\mathrm{MIC}_{50}$ and $\mathrm{MIC}_{90}$ values of 2 and $4 \mu \mathrm{g} / \mathrm{ml}$, respectively.

The two isolates of $C$. lusitaniae were susceptible to amphotericin B (MICs of 0.125 and $0.5 \mu \mathrm{g} / \mathrm{ml}$ ), itraconazole (MICs of 0.03 and $0.015 \mu \mathrm{g} / \mathrm{ml}$ ) and fluconazole (MICs of 0.25 and $0.5 \mu \mathrm{g} / \mathrm{ml})$. Regarding to 5 -flucytosine, one isolate was susceptible (MIC $=0.125 \mu \mathrm{g} / \mathrm{ml}$ ) and the other was intermediate $(\mathrm{MIC}=8 \mu \mathrm{g} / \mathrm{ml})$.

Isolates of C. guilliermondii (3) were all susceptible to amphotericin B (MICs of 0.05 and $1 \mu \mathrm{g} / \mathrm{ml}$ ), 5-flucytosine (MICs of $0.125 \mu \mathrm{g} / \mathrm{ml}$ ) and fluconazole (MICs of 4 and 8 $\mu \mathrm{g} / \mathrm{ml})$. Otherwise, all three isolates had susceptibility dose dependent to itraconazole (MICs of $0.5 \mu \mathrm{g} / \mathrm{ml}$ ).

TABLE II

Antifungal susceptibility profile of $98^{a}$ Candida bloodstream isolates

\begin{tabular}{|c|c|c|c|c|}
\hline \multirow[b]{2}{*}{ Species (no.) } & \multirow[b]{2}{*}{ Antifungal agent } & \multirow[b]{2}{*}{ Range } & \multirow{2}{*}{$\frac{\mathrm{MIC}(\mu \mathrm{g} / \mathrm{ml})}{\mathrm{MIC}_{50}}$} & \multirow[b]{2}{*}{$\mathrm{MIC}_{90}$} \\
\hline & & & & \\
\hline C. albicans & Amphotericin B & $0.125-1$ & 0.5 & 0.5 \\
\hline \multirow[t]{3}{*}{ (43) } & Flucytosine & $0.125-64$ & 0.125 & 0.125 \\
\hline & Fluconazole & $0.125-0.5$ & 0.25 & 0.5 \\
\hline & Itraconazole & $0.007-0.03$ & 0.015 & 0.03 \\
\hline \multirow{4}{*}{$\begin{array}{l}\text { C. tropicalis } \\
(25)\end{array}$} & Amphotericin B & $0.25-1$ & 0.5 & 1 \\
\hline & Flucytosine & 0.125 & 0.125 & 0.125 \\
\hline & Fluconazole & $0.125-0.5$ & 0.25 & 0.5 \\
\hline & Itraconazole & $0.007-0.06$ & 0.015 & 0.03 \\
\hline \multirow{4}{*}{$\begin{array}{l}\text { C. parapsilosis } \\
(22)\end{array}$} & Amphotericin B & $0.25-1$ & 0.5 & 1 \\
\hline & Flucytosine & $0.125-1$ & 0.125 & 0.125 \\
\hline & Fluconazole & $0.125-2$ & 0.5 & 2 \\
\hline & Itraconazole & $0.007-0.06$ & 0.03 & 0.03 \\
\hline \multirow{4}{*}{$\begin{array}{l}\text { C. glabrata } \\
(8)\end{array}$} & Amphotericin B & $0.5-1$ & 0.5 & 0.5 \\
\hline & Flucytosine & 0.125 & 0.125 & 0.125 \\
\hline & Fluconazole & $2-8$ & 2 & 4 \\
\hline & Itraconazole & $0.015-0.5$ & 0.125 & 0.5 \\
\hline
\end{tabular}

a: isolates of C. lusitaniae (2) and C. guilliermondii (3) were not included on this Table. 


\section{DISCUSSION}

Sandven (2000) reviewed 24 studies addressing episodes of candidemia in United States tertiary care hospitals and observed that the incidence of $C$. albicans isolates ranged from $38.8 \%$ to $79.4 \%$ of all episodes. The most prevalent non-albicans Candida species reported by the mentioned studies were $C$. glabrata, $C$. tropicalis and $C$. parapsilosis.

Indeed, in most recent studies of candidemia conducted in United States hospitals, C. glabrata accounted for 10\% to $21 \%$ of all candidemic episodes (Pfaller et al. 1998, 1999, 2000, 2001).

Studies from Canada showed a different picture from the United States. In five out of six studies addressing the epidemiology of candidemia, the incidence of C. albicans isolates ranged from $53 \%$ to $74 \%$ and the non-albicans Candida species were correspondingly less prevalent. The high prevalence of $C$. albicans in Canada resembles the occurrence of this species in some European countries (Taylor et al. 1994, Karlowsky et al. 1997, Philips et al. 1997, Yamamura et al. 1999).

According to data from SENTRY and EORTC surveys, performed between 1997 and 1999, the incidence of $C$. albicans at European centers ranges from 49\% (EORTC) to $59 \%$ (SENTRY) of all episodes of candidemia (Viscoli et al. 1999, Pfaller et al. 2001). Voss et al. (1996), after evaluating 626 episodes of candidemia in five Dutch's hospital observed that C. albicans isolates accounted for $60 \%$ of all episodes. However, in the same study, the incidence of non-albicans Candida species raised from 20 to $40 \%$ between 1987 and 1995.

In the present study we observed that $C$. albicans is the most frequent etiologic agent of candidemia in tertiary care hospitals from four Latin American countries, but non-albicans Candida species responded for almost $60 \%$ of all cases. In contrast with most series of candidemia from the United States and Europe, in which C. glabrata has been increasingly reported, this species represented only $7.5 \%$ of our candidemic episodes (Voss et al. 1996, Abi-Said et al. 1997). The low incidence of infections by primary azole resistant species of Candida may be related to the limited use of fluconazole in our hospitals due to cost considerations (Colombo et al. 1999). However, considering the lack of information regarding to the consume of antifungal drugs in Latin American Hospitals, this hypothesis should be appropriately evaluated by further investigations.

In our casuistic, $C$. tropicalis was the second most frequently isolated species. The emergence of $C$. tropicalis as an important etiologic agent of candidemia in north hemisphere countries has been reported by several authors (Nguyen et al. 1996, Pfaller et al. 2000, 2001).

Rodero et al. (1999) identified C. tropicalis as the second most common isolate related to candidemic episodes during a multicenter study performed with the participation of 12 medical centers located in Argentina, where 89 cases were evaluated. In accordance with our findings, Colombo et al. (1999) reported that $C$. parapsilosis and $C$. tropicalis were the two most common non-albicans Candida species among 145 candidemic episodes documented during a 18 month-period study including 6 different hospitals in Brazil. Costa et al. (2000), after evaluating 86 consecutive episodes of candidemia documented in a single tertiary care hospital from São Paulo, observed that $C$. parapsilosis and C. tropicalis responded for most of all non-albicans Candida isolates. Finally, Pfaller et al. (2001) reported that in Latin American hospitals participating of SENTRY, C. parapsilosis was the second most common Candida species causing blood stream infections.

Most of our Candida bloodstream isolates were susceptible to all antifungal drug tested. However, we had one strain of $C$. albicans and other of $C$. lusitaniae that were resistant and intermediate, respectively, to 5-FC. Isolates of $C$. albicans primarily resistant to 5-FC have been identified in different clinical materials by several authors, varying in frequency between $0 \%$ and $38 \%$ (Iwata 1992 , Barchiesi et al. 2000). The relationship between resistance to 5-FC in C. albicans and serological type was investigated by Drouhet et al. (1975), who reported that the percentage of 5FC-resistant strains isolated from patients in Africa was higher than that recovered from patients in Europe. They suggested that the high incidence of resistance among the former strains was related to the predominance of serotype B isolates (Drouhet et al. 1975).

We were surprised by the low MIC values exhibited by our $C$. glabrata isolates. Several publications from north hemisphere countries have shown that $C$. glabrata isolates usually exhibit high fluconazole MIC values (Voss et al. 1996, Rex et al. 1997, Pfaller et al. 2001). According to SENTRY data, C. glabrata blood stream isolates have $\mathrm{MIC}_{50}$ and $\mathrm{MIC}_{90}$ values ranging from 4 to 16 $\mu \mathrm{g} / \mathrm{ml}$ and 16 to $32 \mu \mathrm{g} / \mathrm{ml}$, respectively. In our series, all $C$. glabrata isolates had MICs values $\leq 8$. This aspect may be also related to the higher use of fluconazole in Europe and United States compared to Latin America.

It is noteworthy that we were able to identify two cases of candidemia due to C. lusitaniae (one reported in Brazil and the other in Argentina) and three cases of $C$. guilliermondii. Both pathogens have been rarely reported in different series of candidemia. Data from the Sentry Program (Pfaller et al. 2001) did not mention any specific data related to the identification of $C$. lusitaniae and $C$. guilliermondii candidemic episodes.

Luzzati et al. (2000) were able to identify three cases of invasive infection due to C. Iusitaniae among 189 candidemic episodes reported in the University Hospital of Verona, during the period of 1992 and 1997. In Latin America, Colombo et al. (1999) reported only three cases of candidemia due $C$. guilliermondii among 145 episodes reported on six different tertiary care hospitals in Brazil.

Some authors advocate that $C$. lusitaniae isolates may present innate resistance to amphotericin B (Pfaller et al. 1994, Hadfield et al. 1997). However, the amphotericin B MIC results exhibited by both isolates of $C$. lusitaniae from our series were 0.125 and $0.5 \mu \mathrm{g} / \mathrm{ml}$ respectively. This aspect may be related to the limitations of the methodology we used to recognize isolates truly resistant to amphotericin B. The NCCLS methodology yields a range of MICs that span only three to four twofold serial dilutions, what make difficult a reliable discrimination between sus- 
ceptible and resistant isolates (Rex et al. 1995). Considering the mentioned limitation of the NCCLS methodology, some authors have suggested to use the Etest with standardized RPMI medium supplemented with $2 \%$ glucose as the most sensitive and reliable means for detecting amphotericin B resistance (Wanger et al. 1995, Peyron et al. 2001).

Although C. albicans continues to account for approximately one-half of all episodes of candidemia reported worldwide, its frequency may vary widely from institution to institution. We were able to demonstrate that in South America most non-albicans Candida species are represented by $C$. tropicalis and $C$. parapsilosis isolates still susceptible to amphotericin B and fluconazole. However, continuously surveillance programs are needed in order to identify possible changes in the species distribution and antifungal susceptibility patterns of yeasts, particularly after increasing the use of azoles in Latin American hospitals.

\section{REFERENCES}

Abi-Said D, Anaisse E, Uzun O, Raad I, Pinzcowski H, Vartivarian S 1997. The epidemiology of hematogenous candidiasis caused by different Candida species. Clin Infect Dis 24: 1122-1128.

Barchiesi F, Arzeni D, Caselli F, Scalesi G 2000. Primary resistance to flucytosine among clinical isolates of Candida spp. J Antimicrob Chemother 25: 408-409.

Baumgartner C, Freydiere AM, Gille Y 1996. Direct identification and recognition of yeast species from clinical material by using Albicans ID and CHROMagar Candida plates. J Clin Microbiol 34: 454-456.

Colombo AL, Nucci M, Salomão R, Branchini ML, Richtmann R, Derossi A, Wey BS 1999. High rate of non-albicans candidemia in Brazilian tertiary care hospitals. Diagn Microbiol Infect Dis 34: 281-286

Costa SF, Marinho I, Araujo EA, Manrique AE, Medeiros EA, Levin AS 2000. Nosocomial fungaemia: a 2-year prospective study. $J$ Hosp Infect 45: 69-72.

Drouhet E, Mercier-Soucy L, Montplaisir S 1975. Sensitivity and resistance of pathogenic yeasts to 5-fluoropyrimidines. Relation between the phenotypes of resistance to 5 fluorocytosine, the serotype of Candida albicans and the ecology of various species of Candida of human origin. Ann Microbiol 126: 25-39.

Ghannoum M, Rex JH, Galgiani JN 1996. Susceptibility testing of fungi: current status of correlation in vitro data with clinical outcome. J Clin Microbiol 34: 489-495.

Hadfield TL, Smith MB, Winn RE, Rinaldi MG, Guerra C 1997. Mycoses caused by Candida lusitaniae. Rev Infect Dis 9: 1006-12.

Iwata K 1992. Drug resistance in human pathogenic fungi. Eur J Epidemiol 8: 407-421.

Karlowsky JA, Zhanel GG, Klym KA, Hoban DJ, Kabani AM 1997. Candidemia in a Canadian tertiary care hospital from 1976 to 1996. Diagn Microbiol Infect Dis 29: 5-9.

Krcmery V, Barnes AJ 2002. Non-albicans Candida spp. causing fungaemia: pathogenicity and antifungal resistance. J Hosp Infect 50: 243-260.

Lunel F M V, Meis JFGM, Voss A 1999. Nosocomial fungal ingections: candidemia. Diagn Microbiol Infect Dis 34: 213220.

Luzzati R, Amalfitano G, Lazzarini L, Soldani F, Bellino S, Solbiati M, Danzi MC, Vento S, Todeschini G, Vivenza C, Concia E 2000. Nosocomial candidemia in non-neutropenic patients at an Italian tertiary care hospitals. Eur J Clin Microbiol Infect Dis 19: 602-607.

NCCLS-National Committee for Clinical Laboratory Standards 2002. Publication M27-A2: Reference method for broth dilution antifungal susceptibility testing of yeasts; approved standard, Wayne, PA: NCCLS 22: 1-29.

Nguyen MH, Clancy CJ, Yu VL, Yu YC, Morris AJ, Snydam DR, Sutton DA, Rinaldi MG 1998. Do in vitro susceptibility data predict microbiologic response to amphotericin B? Results of a prospective study of patients with Candida fungemia. J Infect Dis 177: 425-430.

Nguyen MH, Peacock JE, Morris AJ, Tanner DC, Nguyen ML, Snydman DR, Wagener MN, Rinaldi MG, Yu VL 1996. The changing face of candidemia: emergence of non-Candida albicans species and antifungal resistance. Am J Med 100: 617-623.

Peyron F, Favel A, Nguyen AM, Gilly M, Regli P, Bolmström A 2001. Improved detection of amphotericin B-resistant isolates of Candida lusitaniae by Etest. J Clin Microbiol 39: 339-342.

Pfaller MA, Diekema DJ, Jones RN, Sader HS, Fluit AC, Hollis RJ, Messer AS 2001. International surveillance of bloodstream infections due to Candida species: frequency of occurrence and in vitro susceptibilities to fluconazole, ravuconazole, and voriconazole of isolates collected from 1997 through 1999 in the SENTRY Antimicrobial Surveillance Program. J Clin Microbiol 39: 3254-3259.

Pfaller MA, Jones RN, Doern GV, Fluit AC, Verhoef J, Sader HS, Messer SA, Houston A, Coffman S, Hollis RJ 1999. International surveillance of blood stream infections due to Candida species in the European SENTRY program: species distribution and antifungal susceptibility including the investigational triazole and echinocandin agents. Diagn Microbiol Infect Dis 35: 19-25.

Pfaller MA, Jones RN, Doern GV, Sader HS, Messer SA, Houston A, Coffman S, Hollis RJ 2000. Bloodstream infections due to Candida species: SENTRY Antimicrobial Surveillance Program in North America and Latin America, 19971998. Antimicrob Agents Chemother 44: 747-751.

Pfaller MA, Jones RN, Messer SA, Edmond MB, Wenzel RP 1998. National surveillance of nosocomial blood stream infections due to species of Candida other than Candida albicans: frequency of occurrence and antifungal susceptibility in the SCOPE program. Diagn Microbiol Infect Dis 30: 121-129.

Pfaller MA, Messer SA, Hollis RJ 1994. Strain delineation and antifungal susceptibilities of epidemiologically related and unrelated isolates of Candida lusitaniae. Diagn Microbiol Infect Dis 20: 127-133.

Phillips P, Shafran S, Garber G, Rotstein C, Smaill F, Fong I, Salit I, Miller M, Williams K, Conly JM, Singer J, Ioannou S 1997. Multicenter randomized trial of fluconazole versus amphotericin B for treatment of candidemia in non-neutropenic patients. Eur J Clin Microbiol Infect Dis 16: 337-345.

Rex JH, Cooper CR, Merz WG, Galgiani JN, Anaissie EJ 1995. Detection of amphotericin B-resistant Candida isolates in a broth-based system. Antimicrob Agents Chemother 39: 906-909.

Rex JH, Pfaller MA, Galgiani JN, Bortlett MS, Espinel-Ingroff A, Ghannoum MA, Lancaster M, Odds FC, Rinaldi MG, Walsh TJ, Barry AL 1997. Development of interpretive breakpoints for antifungal susceptibility testing: conceptual framework and analysis of in vitro correlation data for fluconazole, itraconazole and Candida infections. Clin Infect Dis 24: 235-247.

Rodero L, Davel, G, Cordoba S, Soria M, Canteros C, 
Hochenfellner F 1999. Estudio multicéntrico sobre candidiasis nosocomial en la República Argentina. Rev Argent Microbiol 31: 114-119.

Sandven P 2000. Epidemiology of candidemia. Rev Iberoam Micol 17: 73-81.

Taylor GD, Buchanan-Chell M, Kirkland T, McKenzie M, Wiens R 1994. Trends and sources of nosocomial fungaemia. Mycoses 37: 187-190.

Viscoli C, Girmenia C, Marinus A, Collette L, Martino P, Vandercam B, Doyen C, Lebeau B, Spence D, Kremery V, De Pauw B, Meunier F 1999. Candidemia in cancer patients: a prospective, multicenter surveillance study by the Invasive Fungal Infection Group (IFIG) of the European Organization for Research and Treatment of Cancer (EORTC). Clin Infect Dis 28: 1071-1079.

Voss A, Kluytamans JA, Koeleman JG, Spanjaard L, Vandenbroucke-Grauls CMJE, Verbrughb HA, Voss MC,
Weersink AYL, Hoogkamp-Korstanje JAA, Meis JFGM 1996. Occurrence of yeast bloodstream infections between 1987 and 1995 in five Dutch university hospitals. Eur $J$ Clin Microbiol Infect Dis 15: 909-912.

Wanger A, Mills K, Nelson PW, Rex JH 1995. Comparison of Etest and national committee for clinical laboratory standars broth macrodilution method for antifungal susceptibility testing: enhanced ability to detect amphotericin B-resistant Candida isolates. Antimicrob Agents Chemother 39: 252022.

Warren NG, Hazen KC 1995. Candida, Cryptococcus and other yeasts of medical importance. In PR Murray, Manual of Clinical Microbiology, ASM, Washington, p. 723-737.

Yamamura DL, Rotstein C, Nicolle LE, Ionnou S 1999. Candidemia at selected Canadian sites: results from the Fungal Diseases Registry of the Canadian Infectious Disease Society. CMAJ 160: 493-499. 